\title{
Optimal Threshold Estimation Using Prototype Selection
}

\author{
Uri Lipowezky and Victor Shenkar
}

Tiltan System Engineering Ltd.

35 Hayarkon Street, Beney - Beraq 51204, Israel

Tel $972-3-5780711$

Fax $972-3-5780714$

Uri@tiltan-se.co.il

\begin{abstract}
A technique is proposed for choosing the thresholds for a number of object detection tasks, based on a prototype selection technique. The chosen prototype subset has to be correctly classified. The positive and negative objects are introduced in order to provide the optimization via empirical risk minimization. A Boolean function and its derivatives are obtained for each object. A special technique, based on the fastest gradient descent, is proposed for the sum of Boolean functions maximization. The method is applied to the detection task of house edges, using its images in aerial photos. It is shown that proposed method can be expanded to solving of a wide range of tasks, connected to the function optimization, while the function is given in vertices of a $2^{n}$ single hyper - cube.
\end{abstract}

Keywords: Prototype selection, Sum of Boolean function optimization, Edge detection.

\section{Introduction}

A wide variety of image processing tasks such as images compression [17], image matching for motion estimation and 3D modeling [2], object decipherment [14], edge detection [4] and so on, demands in its final stage a threshold selection procedure to distinct between correct and incorrect results. Usually these thresholds are supposed to be pre-defined and no techniques are given for their correct choice, in spite of strong influence of these thresholds on the final results. It was shown in previous works [14], that correct parameter estimation can be achieved using two sets of samples: a set of positive samples (objects) $E=\left\{\mathrm{e}_{1}, \mathrm{e}_{2}, \ldots, \mathrm{e}_{\mathrm{m}}\right\}$ and set of negative samples (anti - objects) $A=\left\{a_{1}, a_{2}, \ldots, a_{p}\right\}$. Sometimes [17] it can be found an automatic procedure for object and anti - object detection, however in common case samples are pointed out manually. Every object $e_{i}, a_{j}, i=1, \ldots, m, j=1, \ldots, p$ can be represented by $n$ - dimensional vector of features $\varphi_{1}, \varphi_{2}, \ldots, \varphi_{n}$, where $\varphi_{i} \in R_{1}$ is supposed to be a real value from limited interval $\left[\varphi_{i}^{\min }, \varphi_{i}^{\max }\right]$. Without loss of generality, let us assume that for each i $E\left[\varphi_{i}(E)\right]>E\left[\varphi_{i}(A)\right]$, where $E\left[\varphi_{i}(E)\right]$ and $E\left[\varphi_{i}(A)\right]$ are average values 
of feature $\varphi_{\mathrm{i}}$ distribution for samples of an object and an anti - object. Under this assumption thresholds $t_{i}=\min _{j=1, ., m} \varphi_{i}\left(e_{j}\right) i=1, . ., n$ provide correct classification for all objects and misclassification for anti-objects with values $\forall_{\mathrm{i}=1, \ldots \mathrm{n}}\left\lfloor\varphi_{\mathrm{i}} \geq \mathrm{t}_{\mathrm{j}}\right\rfloor$. In the other words object $e_{i}=\left(X_{i 1}, X_{i 2}, \ldots, X_{i n}\right)$, where $X_{i j}$ is value of feature $\varphi_{j}, j=1, \ldots, n$ for object $e_{i}$, will be correctly classified if for each feature $\varphi_{j}$ value $X_{i j}$ it exceeds or equals to the threshold $t_{j}$, i. e., $\left.\forall_{j} \mid X_{i j} \geq t_{j}\right\rfloor$. To simplify the expression let us introduce a function similar to the Kroenecker notation:

$$
\delta(\mathrm{X}, \mathrm{t})=1 \text { if } \mathrm{X} \geq \mathrm{t} \text { and } 0 \text { oterwise . }
$$

Using (1) the expression for true object classification can be rewritten as

$$
f_{i}=\prod_{j=1}^{n} \delta\left(x_{i j}, t_{j}\right)
$$

(2) becomes one for true classification and zero for misclassification.

The problem is to define optimal thresholds $t_{j}, j=1, . ., n$ in the sense of empirical risk minimization [20], i. e., to minimize functional

$$
\psi=\sum_{\mathrm{i}=1}^{\mathrm{m}}\left[1-\prod_{\mathrm{j}=1}^{\mathrm{n}} \delta\left(\mathrm{x}_{\mathrm{j}}\left(\mathrm{e}_{\mathrm{i}}\right), \mathrm{t}_{\mathrm{j}}\right)\right]+\sum_{\mathrm{i}=1}^{\mathrm{p}} \prod_{\mathrm{j}=1}^{\mathrm{n}} \delta\left(\mathrm{x}_{\mathrm{j}}\left(\mathrm{a}_{\mathrm{i}}\right), \mathrm{t}_{\mathrm{j}}\right),
$$

where $X_{j}\left(e_{i}\right)$ and $X_{j}\left(a_{i}\right)$ are values of feature $\varphi_{j}$ for a object and an anti-object. The first sum of (3) expresses the misclassification rate and it changes in the points $t_{j}=X_{j}\left(e_{i}\right)$. When $t_{j}$ is increased the sum is reduced and vice versa. The second sum of (3) expresses the false alarm rate. It changes in the points $t_{j}=X_{j}\left(a_{i}\right)$ and it decreases when $t_{j}$ is increased, so if there exists a situation $\mathrm{X}_{\mathrm{j}}\left(\mathrm{e}_{\mathrm{i} 1}\right)<\mathrm{X}_{\mathrm{j}}\left(\mathrm{a}_{\mathrm{i} 1}\right) \leq \mathrm{X}_{\mathrm{j}}\left(\mathrm{a}_{\mathrm{i} 2}\right) \leq \ldots \mathrm{X}_{\mathrm{j}}\left(\mathrm{a}_{\mathrm{ik}}\right)<\mathrm{X}_{\mathrm{j}}\left(\mathrm{e}_{\mathrm{i} 2}\right)$ there is no reason to choose any one of $X_{j}\left(a_{i k}\right)$ in order to minimize (3). Thus, it is enough to considerate only values $\mathrm{X}_{\mathrm{j}}\left(\mathrm{e}_{\mathrm{i}}\right)$. If for any feature $\varphi_{\mathrm{j}}$ value $\mathrm{t}_{\mathrm{j}}>\mathrm{X}_{\mathrm{j}}\left(\mathrm{e}_{\mathrm{i}}\right)$ is chosen $\mathrm{e}_{\mathrm{i}}$ will not be correctly classified. Hence, the following approach can be used to threshold selection. There has to be selected a subset $\mathrm{E}^{\prime} \subseteq \mathrm{E}$ of objects $\mathrm{E}$ that should be correctly classified using thresholds

$$
\mathrm{t}_{\mathrm{j}}=\min _{\mathrm{e}_{\mathrm{i}} \in \mathrm{E}^{\prime}} \mathrm{X}_{\mathrm{j}}\left(\mathrm{e}_{\mathrm{i}}\right) \quad \mathrm{j}=1, \ldots, \mathrm{n}
$$

and it has to minimize sum (3). Using this definition the task of threshold selection can be considered as a task of prototype selection (PS).

The PS task has a rather long history. In the works of P. E. Hart [9] and G. W. Gates [8] the PS task was defined as a task of selection the most representative prototypes for $\mathrm{k}-\mathrm{NN}$ classification. To overcome the problems of classification quality 
a hypothesis of local statistical compactness was proposed [6]. There is a number of algorithms in this framework [11], [3], [13]. Some of them e. g., [13] allow combination of features (genes) to generate new prototypes.

Other approaches can be borrowed from the feature selection task. In expression (3) positive samples $e_{i}$ can be treated as a feature set and negative samples can be used for feature selection. All of approaches in the framework of feature selection can be divided into optimal and sub-optimal approaches. The optimal approach involves exhaustive search [10] and mathematical programming approach [7]. The exhaustive search of all available prototype combinations demands $2^{\mathrm{m}} \mathrm{L}$ recognition operations, where $\mathrm{m}$ is the initial number of prototypes and $\mathrm{L}$ is the test sample volume. Evidently it is impractical in case of (3) minimization. The mathematical programming approach demands $\alpha 2^{\mathrm{m}} \mathrm{L}$ operations, where $\alpha \in[0.008 \ldots 0.04]$ also is not applicable for (3) optimization, since $\mathrm{L}=\mathrm{m}+\mathrm{p}$ can be very large.

A sub-optimal approach supposes an existence of a finite set of optimal vertices in a m-dimensional hyper-cube, where each vertex corresponds to a combination of the prototypes. Let us assume, that binary vector $b=\left\{b_{1}, \ldots, b_{m}\right\}$ corresponds to the initial prototype set $E$. If $b_{i}=1$ prototype $e_{i}$ is included into optimal subset $E^{\prime}$. Using random generation of vector $b$ and it substitution into (3) one can choose an optimal $\mathrm{E}^{\prime}$, related to the minimum (3). If there are $\mathrm{N}_{\max }$ optimal subsets $\mathrm{E}^{\prime}$ with the same value (3) the probability to reach one of them is $\mathrm{p}=\mathrm{N}_{\max } / 2^{\mathrm{m}}$ and hence [15] it is enough

$$
\mathrm{T}=-2^{\mathrm{m}} \ln (1-\eta) / \mathrm{N}_{\max }
$$

runs of a search algorithm to reach a global minimum with probability $\eta$. There are two main directions in the framework of the sub-optimal approach, yielding a single solution of the problem. They are deterministic and stochastic approaches [10]. The stochastic approach [1] is based on a punishment and encouragement technique for different subsets. It is similar to genetic approach [13] and actually converges to an adaptive random search. The family of deterministic algorithms [12] can be represented for (3) optimization by forward and backward methods, which are based on sequential deleting/addition of an appropriate prototype.

Sometimes as for 1-NN classification [15] functional (3) can be expressed analytically in respect to probabilities of prototypes present in the optimal subset, and the optimal subset can be found using classical optimization procedures [3]. The purpose of the work is to show that this approach is also possible for (3) minimization and so one can derived an algorithm that combines the advances of the above mentioned approaches.

In Section 2 an illustrative example for $n=1$ is given. In Section 3 an algorithm for the common $n$-dimensional case is developed. Section 5 includes experiments and conclusions. 


\section{One-Dimensional Case}

Let us consider an illustrative example of threshold selection. Let $n=1$ be the number of features, $E=\left\{e_{1}, . ., e_{m}\right\}$ is an initial prototype set, where prototypes are sorted up so that $\varphi\left(\mathrm{e}_{\mathrm{m}}\right)>\varphi\left(\mathrm{e}_{\mathrm{m}-1}\right)>\ldots>\varphi\left(\mathrm{e}_{1}\right)$ and $\mathrm{A}=\left\{\mathrm{a}_{1}, . ., \mathrm{a}_{\mathrm{p}}\right\}$ is a set of negative objects which are also sorted up. If threshold $t$ is chosen using (4) $e_{1}$ is recognized correctly if and only if $e_{1} \in E^{\prime}$. Prototype $e_{2}$ can be classified correctly if $e_{1}$ or $e_{2}$ are included into $E^{\prime}$, since $\varphi\left(e_{1}\right) \leq \varphi\left(e_{2}\right)$ and so on $e_{i}$ can be recognized if one of $e_{j}, j \leq i$ is included into $E^{\prime}$. Using a set of Boolean variables $b=\left\{b_{1}, \ldots, b_{m}\right\}$, where each $b_{i}$ is associated with $e_{i}$ the condition for $e_{i}$ correct classification can be written as $f\left(e_{i}\right)=b_{1} \vee b_{2} \vee \ldots b_{i}=\vee_{j=1}^{i} b_{j}$ and for negative object $f\left(a_{i}\right)=\underset{\varphi\left(e_{j}\right) \leq \varphi\left(a_{i}\right)}{\vee} b_{j}$. Since the aim is to recognize $e_{i}$ and not to recognize $a_{i}$ functional (3) can be rewritten as

$$
\psi(b)=\sum_{i=1}^{m}\left(\bigvee_{j=1}^{i} b_{j}=\text { true }\right)+\sum_{i=1}^{p}\left(\neg \underset{\varphi\left(e_{j}\right) \leqslant \varphi\left(a_{i}\right)}{\bigvee} b_{j}=\text { true }\right)
$$

Let us assume that $0 \leq \mathrm{p}_{\mathrm{i}} \leq 1$ is a fuzzy variable [19] associated with $\mathrm{e}_{\mathrm{i}}$. If a lot of subsets $E^{\prime}$ are obtained using a random generation, then $\mathrm{p}_{\mathrm{i}}$ means a probability that prototype $e_{i}$ belongs to the optimal prototype subset. Hence, $q_{i}=1-p_{i}$ means a fuzzy variable associated with $\overline{e_{i}}$. Since prototypes are supposed to be independent (6) can be rewritten using $\mathrm{q}_{\mathrm{i}}$ as follows

$$
\psi(Q)=\sum_{i=1}^{m}\left(1-\prod_{j=1}^{i} q_{j}\right)+\sum_{i=1}^{p} \prod_{\varphi\left(e_{j}\right) \leqslant \varphi\left(a_{i}\right)} q_{j}
$$

The problem is to find maximum of the analytical function $\psi(\mathrm{Q})$, where $\mathrm{Q}=\left\{\mathrm{q}_{1}, \ldots, \mathrm{q}_{\mathrm{m}}\right\}$. There are some properties of (7) that makes the problem easier. It follows from (7) that every $\mathrm{q}_{i}$ is represented in each multiplication not more than once. Therefore for every $q_{i}$

$$
\frac{\partial^{2} \psi\left(\mathrm{q}_{1}, \mathrm{q}_{2}, \ldots, \mathrm{q}_{\mathrm{m}}\right)}{\partial \mathrm{q}_{\mathrm{i}}^{2}}=0
$$

Such a function can be called poly-line function [15]. Generally speaking, there is no problem to calculate derivatives of the poly-line function. For instance, in case (7) the expression for derivative is 


$$
\frac{\partial \psi}{\partial q_{k}}=-\sum_{i=k}^{m} \prod_{j=1}^{k-1} q_{j} \prod_{j=k+1}^{i} q_{j}+\sum_{\varphi\left(a_{i}\right) \leq \varphi\left(e_{k}\right)} \prod_{\varphi\left(e_{j}\right) \leq \varphi\left(a_{i}\right) ; j \neq k} q_{j}
$$

So calculations of the gradient almost do not demand additional operations and optimization based the fastest gradient descent [5] can be used. From (9) it follows that $-\mathrm{m} \leq \partial \psi / \partial \mathrm{q}_{\mathrm{k}} \leq \mathrm{p}$ that fulfils the Lipschiz condition what is necessary for the existence of the maximum (7). Let us prove that poly-line function can be represented as a convex combination of its values in the vertices of $2^{\mathrm{m}}$ single hyper-cube as follows:

$$
\psi\left(\mathrm{q}_{1}, \ldots, \mathrm{q}_{\mathrm{m}}\right)=\sum_{\mathrm{i}=0}^{2^{\mathrm{m}}-1} \lambda_{\mathrm{i}} \psi\left(\mathrm{B}_{\mathrm{m}}(\mathrm{i})\right)
$$

where $0 \leq \lambda_{\mathrm{i}} \leq 1, \sum_{\mathrm{i}=1}^{2^{\mathrm{m}}-1} \lambda_{\mathrm{i}}=1, \lambda_{\mathrm{i}}=\prod_{\mathrm{j}=1}^{\mathrm{m}} \mathrm{y}_{\mathrm{j}}(\mathrm{i})$ and $\mathrm{B}_{\mathrm{m}}(\mathrm{i})$ is binary m-dimensional decomposition of the integer value $i$, where $i$ is one of the vertices and each bit $\mathrm{j}=1, \ldots, \mathrm{m}$ of the decomposition with respect to the associated variable $\mathrm{q}_{\mathrm{j}}$. Variable $y_{j}(i)=q_{j}$ if bit $j$ in $B_{m}(i)$ is equal to one and $y_{j}(i)=1-q_{j}$ otherwise.

Let us consider the following induction. If $\mathrm{m}=1$ poly-line function (10) can be represented as $\psi(\mathrm{q})=\mathrm{aq}+\mathrm{b}$ or using decomposition $\lambda_{0}=1-\mathrm{q}, \lambda_{1}=\mathrm{q}$ so $\lambda_{0}+\lambda_{1}=1$ and $\psi(q)=(a+b) q+b(1-q)$. Let us assume that it is correct for all $\mathrm{m}=1,2, . ., \mathrm{d}$ and let us try to prove that it is correct also for $\mathrm{m}=\mathrm{d}+1$. From (8) it follows that

$$
\psi\left(\mathrm{q}_{1}, . ., \mathrm{q}_{\mathrm{d}}, \mathrm{q}_{\mathrm{d}+1}\right)=\psi_{1}\left(\mathrm{q}_{1}, . ., \mathrm{q}_{\mathrm{d}}\right) \mathrm{q}_{\mathrm{d}+1}+\psi_{2}\left(\mathrm{q}_{1}, . ., \mathrm{q}_{\mathrm{d}}\right),
$$

where $\psi_{1}, \psi_{2}$ are poly-line functions that can be represented in form (10). Substitution (10) into (11) gives

$$
\psi\left(\mathrm{q}_{1}, . ., \mathrm{q}_{\mathrm{d}}, \mathrm{q}_{\mathrm{d}+1}\right)=\sum_{\mathrm{i}=0}^{2^{\mathrm{d}-1}} \lambda_{\mathrm{i}} \mathrm{q}_{\mathrm{d}+1}\left[\psi_{1}\left(\mathrm{~B}_{\mathrm{d}}(\mathrm{i})\right)+\psi_{2}\left(\mathrm{~B}_{\mathrm{d}}(\mathrm{i})\right)\right]+\sum_{\mathrm{i}=0}^{2^{\mathrm{d}-1}} \lambda_{\mathrm{i}}\left(1-\mathrm{q}_{\mathrm{d}+1}\right) \psi_{2}\left(\mathrm{~B}_{\mathrm{d}}(\mathrm{i})^{\prime}\right.
$$

Thus,

$$
\psi\left(\mathrm{q}_{1}, \ldots, \mathrm{q}_{\mathrm{d}}, 1\right)=\psi_{1}+\psi_{2}, \psi\left(\mathrm{q}_{1}, \ldots, \mathrm{q}_{\mathrm{d}}, 0\right)=\psi_{2} \text { and }
$$

$\sum_{\mathrm{i}=0}^{2^{\mathrm{d}}-1} \lambda_{\mathrm{i}} \mathrm{q}_{\mathrm{d}+1}+\lambda_{\mathrm{i}}\left(1-\mathrm{q}_{\mathrm{d}}\right)=\sum_{\mathrm{i}=0}^{2^{\mathrm{d}}-1} \lambda_{\mathrm{i}}=1$. Therefore all values in the hyper-cube are limited within values in its vertices and so a global maximum of (10) can be found only in a vertex of hyper-cube, hence for optimization algorithm it is enough to consider only values $\mathrm{q}_{\mathrm{i}} \in\{0,1\}$.

The main corollary following from this property is that a variety of tasks that are connected with optimization on the $2^{\mathrm{m}}$ hyper-cube, when the values of the functional could be found in every vertex can be solved using poly-line function optimization. However this corollary does not show how this poly-line function and its derivatives 
can be found except of trivial case (10) when all $2^{\mathrm{m}}$ values are known. In most of the pattern recognition tasks functional (3) can be represented as sum of Boolean functions as (6). Let us prove that if Boolean function $F\left(x_{1}, \ldots, x_{n}\right)$ is defined on all of $2^{n}$ sets of variables $x_{i} \in\{0,1\}$, there exists a poly-line function $\psi\left(p_{1}, \ldots, p_{n}\right)$, where $\mathrm{p}_{\mathrm{i}}$ is the probability that $\mathrm{x}_{\mathrm{i}}$ belongs to the optimal subset.

Indeed every Boolean function $\mathrm{F}\left(\mathrm{x}_{1}, \ldots, \mathrm{x}_{\mathrm{n}}\right)$ can be represented using its disjunctive normal form $\mathrm{F}\left(\mathrm{x}_{1}, \ldots, \mathrm{x}_{\mathrm{n}}\right)=\mathrm{x}_{\mathrm{i}} \mathrm{A} \vee \overline{\mathrm{x}}_{\mathrm{i}} \mathrm{B} \vee \mathrm{C}$, where $\mathrm{A}, \mathrm{B}$ and $\mathrm{C}$ do not depend on $x_{i}$. The expectation of $\psi\left(p_{1}, \ldots, p_{n}\right)$ respected to $F\left(x_{1}, \ldots, x_{n}\right)$ is

$$
\psi\left(\mathrm{p}_{1}, \ldots, \mathrm{p}_{\mathrm{n}}\right)=1-(1-\operatorname{Pr}(\mathrm{C}))\left(1-\operatorname{Pr}\left(\mathrm{x}_{\mathrm{i}} \mathrm{A} \vee \overline{\mathrm{x}}_{\mathrm{i}} \mathrm{B} \mid \mathrm{C}\right)\right) .
$$

Since events $\mathrm{x}_{\mathrm{i}} \mathrm{A}$ and $\overline{\mathrm{x}}_{\mathrm{i}} \mathrm{B}$ are independent (12) can be rewritten as

$$
\psi\left(\mathrm{p}_{1}, \ldots, \mathrm{p}_{\mathrm{n}}\right)=1-[\operatorname{Pr}(\mathrm{C})]\left\{\mathrm{p}_{\mathrm{i}}[\operatorname{Pr}(\mathrm{A} \mid \mathrm{C})-\operatorname{Pr}(\mathrm{B} \mid \mathrm{C})]-1-\operatorname{Pr}(\mathrm{B} \mid \mathrm{C})\right\} .
$$

and hence, $\partial^{2} \psi / \partial \mathrm{p}_{\mathrm{i}}^{2}=0$. Since $\mathrm{x}_{\mathrm{i}}$ is an arbitrary variable (13) is correct for any $\mathrm{i}=1, . ., \mathrm{n}$. Formula (17) gives the technique to solve task (3) in common case.

\section{Common n-Dimensional Case}

Let us consider once more expression (2). Object $e_{i}$ will be correctly classified if $\mathrm{f}_{\mathrm{i}}=\underset{\mathrm{j}=1}{\mathrm{n}} \underset{\mathrm{X}_{\mathrm{jk}} \leq \mathrm{X}_{\mathrm{ji}}}{\vee \mathrm{e}_{\mathrm{k}}}$ is true. Using disjunctive form the same expression can be written also for an anti-object as follows:

$$
\overline{\mathrm{f}}_{\mathrm{i}}=\mathrm{a}_{\mathrm{i}}=\underset{\mathrm{j}=1}{\mathrm{n}} \underset{\mathrm{X}_{\mathrm{jk}} \leq \mathrm{X}_{\mathrm{ji}}}{\mathrm{V}}
$$

If it is supposed that $\mathrm{f}_{\mathrm{i}}, \mathrm{a}_{\mathrm{i}}=1$ if (14) is true and zero if it is false, the maximum of $\psi=\sum_{\mathrm{i}=1}^{\mathrm{m}} \mathrm{f}_{\mathrm{i}}+\sum_{\mathrm{i}=1}^{\mathrm{p}} \mathrm{a}_{\mathrm{i}}$ is equal to minimum of (3). Any one of expressions (14) can be simplified using common variable extraction: $a b \vee a c=a(b \vee c)$ and group elimination: $\mathrm{ab} \vee \mathrm{a}=\mathrm{a}$ and hence, (14) can be represented as

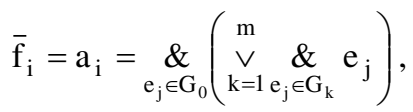

where $\mathrm{G}_{0}$ is common group, $\mathrm{m} \leq \mathrm{n}$ is reduced number of groups and $\mathrm{G}_{\mathrm{k}}$ is a partial group.

Let us find derivatives of (15). Since inclusion of any $\mathrm{e}_{\mathrm{i}}$ does not depend on inclusion exclusion of any other $e_{j}, j \neq i$ into the optimal subset, it can be written: 


$$
1-\mathrm{f}_{\mathrm{i}}=\mathrm{a}_{\mathrm{i}}=\prod_{\mathrm{j} \in \mathrm{G}_{0}}\left(1-\mathrm{p}_{\mathrm{j}}\right) \operatorname{Pr}\left(\bigvee_{\mathrm{k}=1}^{\mathrm{m}} \underset{\mathrm{e}_{1} \in \mathrm{G}_{\mathrm{k}}}{\&} \overline{\mathrm{e}}_{1}\right)
$$

from (16) is follows that for any $e_{j} \in G_{0}$

$$
\frac{\partial \mathrm{f}_{\mathrm{i}}}{\partial \mathrm{p}_{\mathrm{j}}}=-\frac{\partial \mathrm{a}_{\mathrm{i}}}{\partial \mathrm{p}_{\mathrm{j}}}=\underset{\mathrm{e}_{\mathrm{k}} \in \mathrm{G}_{0}, \mathrm{k} \neq \mathrm{j}}{\&} \overline{\mathrm{e}}_{\mathrm{j}}\left[\mathrm{V}_{\mathrm{k}=1}^{\mathrm{m}} \underset{\mathrm{e}_{1} \in \mathrm{G}_{\mathrm{k}}}{\&} \overline{\mathrm{e}}_{\mathrm{l}}\right]
$$

For any $\mathrm{e}_{\mathrm{j}} \in \mathrm{G}_{\mathrm{k}}$ expression (15) in parenthesis can be written as

$$
\begin{aligned}
& \mathrm{R}=\vee_{\mathrm{k}=1}^{\mathrm{m}} \boldsymbol{\&}_{\mathrm{e}_{\mathrm{j}} \in \mathrm{G}_{\mathrm{k}}} \overline{\mathrm{e}}_{\mathrm{j}}=\overline{\mathrm{e}}_{\mathrm{j}} \mathrm{F}_{1} \vee \mathrm{F}_{2}, \quad \text { where } \quad \mathrm{F}_{1}=\vee_{\mathrm{G}_{\mathrm{k}} \supseteq \mathrm{e}_{\mathrm{j}}} \boldsymbol{\&}_{\mathrm{e}_{1} \in \mathrm{G}_{\mathrm{k}}, l \neq \mathrm{j}} \overline{\mathrm{e}}_{1} \text { and } \\
& \mathrm{F}_{2}=V_{\mathrm{G}_{\mathrm{k}} \not \subset \mathrm{e}_{\mathrm{j}}} \boldsymbol{\&}_{\mathrm{e}_{1} \in \mathrm{G}_{\mathrm{k}}, \mathrm{l \neq j}} \overline{\mathrm{e}}_{1} \text {. The derivative of } \mathrm{R} \text { is }
\end{aligned}
$$$$
\mathrm{dR} / \mathrm{de}_{\mathrm{j}}=\mathrm{R}\left(\mathrm{e}_{\mathrm{j}}=1\right)=\mathrm{R}\left(\mathrm{e}_{\mathrm{j}}=0\right)=\mathrm{F}_{2}-\mathrm{F}_{1} \vee \mathrm{F}_{2}=-\mathrm{F}_{1} \mathrm{~F}_{2} \text { and finally }
$$

$$
\frac{\partial \mathrm{f}_{\mathrm{i}}}{\partial \mathrm{e}_{\mathrm{j}}}=-\frac{\partial \mathrm{a}_{\mathrm{i}}}{\partial \mathrm{e}_{\mathrm{j}}}=\underset{\mathrm{e}_{1} \in \mathrm{G}_{0}}{\&} \overline{\mathrm{e}}_{1}\left(\underset{\mathrm{G}_{\mathrm{k}} \supseteq \mathrm{e}_{\mathrm{j}} \mathrm{e}_{\mathrm{l}} \in \mathrm{G}_{\mathrm{k}}}{\mathrm{\&}} \overline{\mathrm{e}}_{1}\right)\left(\underset{\mathrm{G}_{\mathrm{k}} \not \mathrm{e}_{\mathrm{j}} \mathrm{e}_{1} \in \mathrm{G}_{\mathrm{k}}}{\&} \underset{\mathrm{V}}{\mathrm{V}} \mathrm{e}_{1}\right)
$$

Since $\mathrm{f}_{\mathrm{i}}, \mathrm{a}_{\mathrm{i}}$ and their derivatives could be calculated using the same groups $\mathrm{G}_{\mathrm{k}}$ computation of the gradient $\operatorname{grad} \psi=\left(\mathrm{g}_{1}, \ldots, \mathrm{g}_{\mathrm{n}}\right)$ almost does not demand additional operations. It allows us to derive the following optimization algorithm, based on gradient descent [5].

1. For every $f_{i}, i=1, . ., m$ and $a_{i}, i=1, . ., p$ obtain formulae (15) and save them via groups $\mathrm{G}_{\mathrm{k}}, \mathrm{k}=0,1, .$.

2. Using random generation, choose an arbitrary vertex $Q=\left(q_{1}, . ., q_{n}\right)$, where $\mathrm{q}_{\mathrm{i}} \in\{0,1\}$.

3. For a chosen vertex $\mathrm{Q}$ calculate $\psi$ and $\operatorname{grad} \psi=\left(\mathrm{g}_{1}, \ldots, \mathrm{g}_{\mathrm{n}}\right)$, where each derivative $g_{i}$ is sum of (17), (18) for all $f_{i}$ and $a_{i}$.

4. Define next vertex $\mathrm{P}=\left(\mathrm{p}_{1}, . ., \mathrm{p}_{\mathrm{n}}\right)$, where $\mathrm{p}_{\mathrm{i}}=\mathrm{q}_{\mathrm{i}}$ if $\mathrm{q}_{\mathrm{i}}=1$ and $\mathrm{g}_{\mathrm{i}} \geq 0$ or $\mathrm{q}_{\mathrm{i}}=0$ and $\mathrm{g}_{\mathrm{i}} \leq 0$. Otherwise $\mathrm{p}_{\mathrm{i}}=1-\mathrm{q}_{\mathrm{i}}$. If $\mathrm{P}=\mathrm{Q}$ (the same vertex) the process is over and local maximum point is reached, otherwise the next step has to be done.

5. If $\psi(P) \geq \psi(Q)+\underset{B}{\max }\left|g_{i}\right|$, where Bincludes indices $i$ for which $p_{i} \neq q_{i}$ as $P$ is the next vertex. Otherwise the next vertex is $\mathrm{Y}=\left(\mathrm{q}_{1}, . ., \mathrm{q}_{\mathrm{j}-1}, 1-\mathrm{q}_{\mathrm{j}}, \mathrm{q}_{\mathrm{j}+1}, . ., \mathrm{q}_{\mathrm{n}}\right)$, where $\mathrm{j}=\arg \max \left|\mathrm{g}_{\mathrm{i}}\right|$.

6. Repeat Steps 2-5 for $\mathrm{N}_{\mathrm{c}}(\eta)$ random vertices, where $\eta$ is the required probability for the reaching a global maximum, typically $\eta=0.95$. The value of $\mathrm{N}_{\mathrm{c}}(\eta)$ can be found using results of [15] $\mathrm{N}_{\mathrm{c}}(\eta) \approx(1+\mathrm{p} / \mathrm{m}) \ln (1-\eta)$. 
7. Select the maximal value $E^{\prime}=\arg \max _{i=1, . ., N_{c}} \psi\left(E_{i}\right)$ among $N_{c}(\eta)$ local maxima. Following [15] the algorithm of local maximum search converges after no more than me $^{\gamma}$ steps $2-5$, where $\gamma=0.577215 \ldots$ is the Euler constant. The average number of steps is $C(m)=\int_{0}^{1} \exp \left(\sum_{i=1}^{m} \frac{\tau^{i}}{i}\right) d \tau$.

\section{Experiments}

Let us consider for example the well-known task of automatic edge detection. The purpose is to detect edges of houses and ignore edges of vegetation using aerial photos. At the first stage of image processing the convolution map $\mathrm{M}(\mathrm{x}, \mathrm{y})=\max _{\varphi, \mathrm{L}}\left|\mathrm{I}(\mathrm{x}, \mathrm{y}) * \mathrm{C}\left(\varphi, \mathrm{L}, \mathrm{x}^{\prime}, \mathrm{y}^{\prime}\right)\right|$ is obtained, where $\mathrm{C}$ is Canny's function [4] of scale of edge $\mathrm{L}$, rotated to angle $\varphi$. Calculation of $\mathrm{M}(\mathrm{x}, \mathrm{y})$ is done using fast Fourier transform. Threshold of $\mathrm{M}(\mathrm{x}, \mathrm{y}) \geq \mathrm{M}_{0}$ is the first parameter. Other parameters can be extracted by applying mask $\mathrm{C}(\varphi, \mathrm{L})=\arg \max \mathrm{M}(\mathrm{x}, \mathrm{y})$ to the image $\mathrm{I}(\mathrm{x}, \mathrm{y})$ in point $(x, y)$. The second parameter is minimal contrast $C_{0}=\max _{x, y \in C} I(x, y)-\min _{x, y \in C} I(x, y)$, the third is minimal median value $\mathrm{m}_{0}=\max (\underset{C(x, y)>0}{\operatorname{med}} \mathrm{I}(\mathrm{x}, \mathrm{y}), \underset{C(x, y)<0}{\operatorname{med}} \mathrm{I}(\mathrm{x}, \mathrm{y}))$. The next three parameters are minimal common standard deviation $\sigma_{0}=\mathrm{D}[\mathrm{I}(\mathrm{x}, \mathrm{y}) \mathrm{I}(\mathrm{x}, \mathrm{y}) \in \mathrm{C}]$, maximal one-side standard deviation $\sigma_{\mathrm{m}}=\min (\mathrm{D}[\mathrm{I}(\mathrm{x}, \mathrm{y}) \mid \mathrm{C}(\mathrm{x}, \mathrm{y})>0], \mathrm{D}[\mathrm{I}(\mathrm{x}, \mathrm{y}) \mid \mathrm{C}(\mathrm{x}, \mathrm{y})<0])$ and relative Student relation $\mathrm{t}=|\mathrm{E}[\mathrm{I}(\mathrm{x}, \mathrm{y}) \mid \mathrm{C}(\mathrm{x}, \mathrm{y})>0]-\mathrm{E}[\mathrm{I}(\mathrm{x}, \mathrm{y}) \mid \mathrm{C}(\mathrm{x}, \mathrm{y})<0]| / \sigma_{\mathrm{m}}$, where $\mathrm{E}[\mathrm{x}]$ and $\mathrm{D}[\mathrm{x}]$ are expectation and standard deviation of variable $\mathrm{x}$. Using this set of six parameters $\mathrm{n}=7, \mathrm{~m}=142$ positive and $\mathrm{p}=180$ negative points edge image of Fig. 1 was received.

\section{Conclusion}

The further development of the maximization method of functions given on the vertices of a n-dimensional single hyper-cube [15] opens the way to decision making in a wide range of well-known pattern recognition tasks such as prototype feature selection, factor analysis, threshold estimation and so on. The only problem to be solved in this way is to obtain a correct expression for Boolean functions and their derivatives such as (15), (17), (18). Theoretically, following theorem (10) it always possible but practically the derivation of these expressions is a special and sometimes complicated task that requires deeply understanding of the being considered problem. 


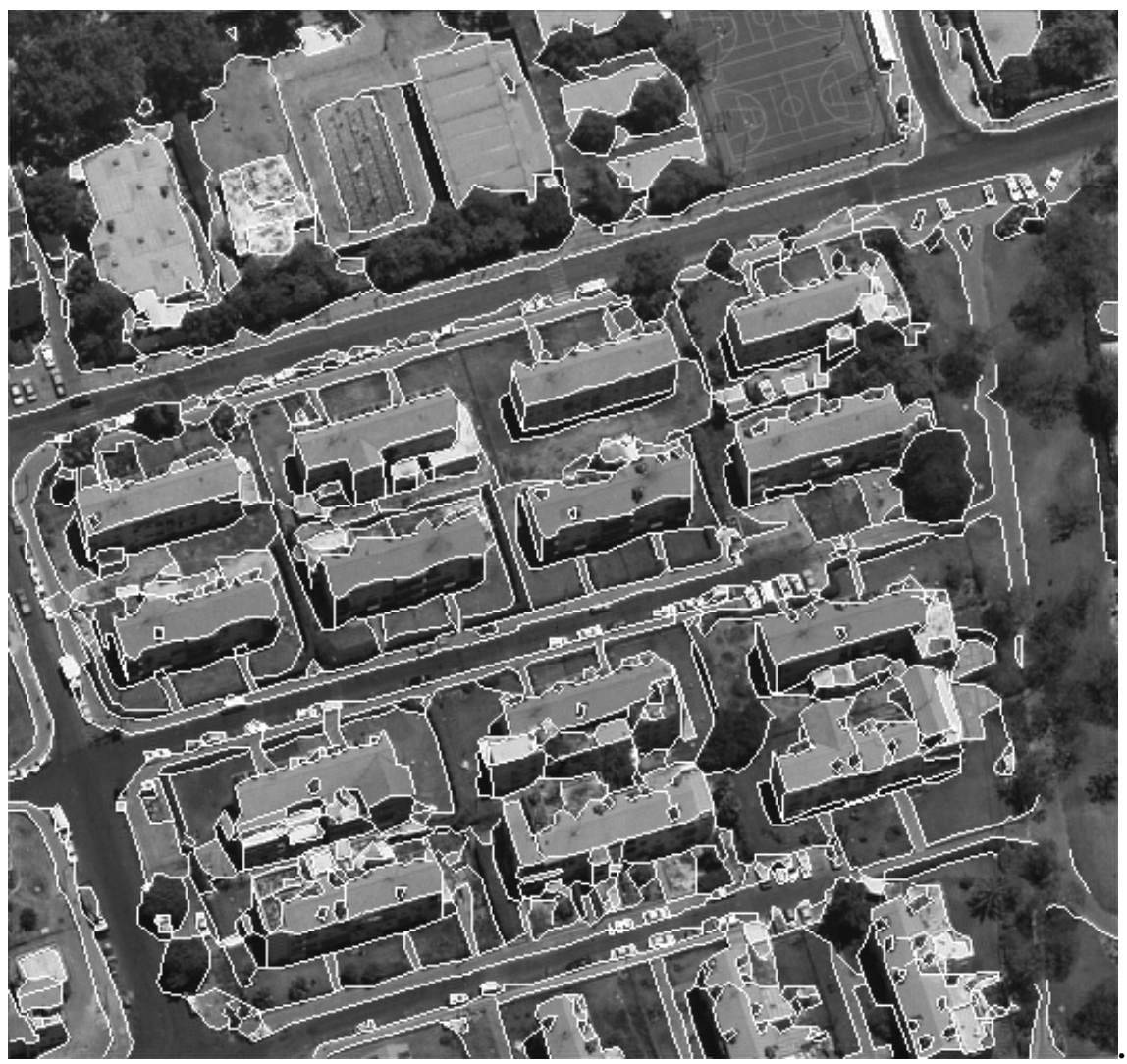

Fig. 1. The result of house edge detection using optimal threshold selection

\section{Acknowledgment}

The authors would like to thank Leah Bar for her help in providing practical information.

\section{References}

1. Antamoshkin, A. A., Saraev, V. M.: On Definition of Informative Subsystem of Signs in the Pattern Recognition Problem. Computers and Artificial Intell. 4 (1985) 245-252

2. Beveridge J. R., Riserman E. M.: How Easy Matching 2D Line Models Using Local Search? IEEE Trans. on Pattern Anal. and Machine Intell. 6(1997) 564-579

3. Decaestecker C.: Finding Prototypes for Nearest Neighbor Classification by Means of Gradient Descent and Deterministic Annealing. Pattern Recognition 30(1997) 281-288 
4. Demigny D., Kamle T.: A Discrete Expression of Canny's Criteria for Step Edge Detector Performances Evaluation. IEEE Trans. on Pattern Anal. and Machine Intell. 19(1977) 1199-1211

5. Dennis J. E. Jr., Schnabel R. B.: Numerical Methods for Unconstrained Optimization and Nonlinear Equations. Prentice-Hall Inc., New Jersey (1983)

6. Devijer P. A., Kittler J.: Pattern Recognition: A Statistical Approach. Prentice-Hall Inc., Englewood Cliffs, N. J. (1982)

7. Foroutan I., Sklansky J.: Feature Selection for Automatic Classification of Non-Gaussian Data. IEEE Trans. on System Man and Cybernetics 17(1987) 187-198

8. Gates G. W.: The Reduced Nearest Neighbor Rule. Trans. on Inf. Theory 18(1972) 431433

9. Hart P. E.: The Condensed Nearest Neighbor Rule. Trans on Inf. Theory 14(1968) 515516

10. Jain A., Zongker D.: Feature Selection: Evaluation, Application and Small Sample Performance. IEEE Trans. on Pattern Anal. and Mach. Intel. 19(1997) 153-158

11. Kim J., Yu J. R., Kim S. H.: Learning of Prototypes and Decision Boundaries for a Verification Problem. Pattern Recognition Lett. 17(1996) 691-697

12. Kittler J.: Feature Set Search Algorithms. In Chen C. H. (ed.): Pattern Recognition and Signal Processing. Sijthoff and Noordhoff, Alphen van der Rijn, The Nethrlands (1978) 41-60

13. Kuncheva L. I.: Editing For the k-Nearest Neighbors Rule by a Genetic Algorithm. Pattern Recognition Lett. 16(1995) 809-814

14. Lipowezky U.: Tree-Plantation Decipherment of Panchromatic Aerial Photo Images Using Supervised Template Matching. In Proc. of 9-th. Mediterranean Electromechanical Conf. Melecon'98, vol. 1 Tel-Aviv (1998) 48-52

15. Lipowezky U.: Selection of the Optimal Prototype Subset for 1-NN Classification. Pattern Recognition Lett. 19(1998) 907-918

16. Sanchez J. S., Fla F., Ferry F. J.: Prototype Selection for the Nearest Neighbor Rule Through Proximity Graph. Pattern Recognition Lett. 18(1997) 507-513

17. Strela V., Heller P. N., Strang G., Topiwala P., Heil C.: The Application of Multi-wavelet Filterbanks for Image Processing. IEEE Trans. on Image Processing 8(1999) 548-563

18. Trier Ø. D., Jain A. K.: Goal-Directed Evaluation of Binarization Methods. IEEE Trans. on Pattern Anal. and Mach. Intel. 17(1995) 1191-1201

19. Vapnik V. N.: Estimation of Dependencies Based on Empirical Data. Springer-Verlag, Berlin Heidelberg (1982)

20. Zadeh L. A.: Fuzzy Sets as a Basis for a Theory of Possibility. Fuzzy Sets Syst. 1(1978) 328 